EMBRYRIDDLE

SCHOLARLY COMMONS
Journal of Aviation/Aerospace

Education \& Research

Volume 15

Number 2 JAAER Winter 2006

Article 8

Winter 2006

\title{
The Application of Scenario Based Recurrent Training to Teach Single Pilot Resource Management (SRM) Under the FAA Industry Training Standards (FITS) Program
}

Francis $\mathrm{H}$. Ayers

ayersf@erau.edu

Follow this and additional works at: https://commons.erau.edu/jaaer

\section{Scholarly Commons Citation}

Ayers, F. H. (2006). The Application of Scenario Based Recurrent Training to Teach Single Pilot Resource Management (SRM) Under the FAA Industry Training Standards (FITS) Program. Journal of Aviation/ Aerospace Education \& Research, 15(2). https://doi.org/10.15394/jaaer.2006.1504

This Article is brought to you for free and open access by the Journals at Scholarly Commons. It has been accepted for inclusion in Journal of Aviation/Aerospace Education \& Research by an authorized administrator of Scholarly Commons. For more information, please contact commons@erau.edu. 


\title{
THE APPLICATION OF SCENARIO BASED RECURRENT TRAINING TO TEACH SINGLE PILOT RESOURCE MANAGEMENT (SRM) UNDER THE FAA INDUSTRY TRAINING STANDARDS (FITS) PROGRAM
}

\author{
Francis H. Ayers, Jr.
}

\begin{abstract}
Research indicates that improving a pilot's capability to exercise sound judgment and make informed and timely decisions may significantly improve flight safety. One approach to this problem is the introduction of scenario-based training (SBT) into flight training curriculums. At the request of the Cirrus Owner's and Pilots Association (COPA), the author developed and conducted four 3-hour scenario based seminars embodying these concepts and collected initial data from the 54 participants. A longitudinal study of this initial group will form the basis for additional research.
\end{abstract}

\section{INTRODUCTION}

Robert Wright, Manager of the General Aviation and Commercial Division of the Federal Aviation Administration, identified a new way of looking at General Aviation flight safety based on the intended utilization of the aircraft (2002). In his "White Paper" he predicted that the introduction of a new class of "Technically Advanced Aircraft" (TAA) would have a significant effect on general aviation safety. A recently completed study of TAA accidents and incidents (Fiduccia, 2003, pp. 19) appears to support this assessment. The study concluded that these TAA's, which generally include an Instrument Flight Rules (IFR) capable moving map Global Positioning System (GPS), multifunction display, and an autopilot, provided an increased level of "available safety" while delivering less actual safety (Fiduccia 2003, pp.6). The TAA Safety Study concluded that "Realistic Scenario Based" training is one solution to filling the gap between available and actual safety. This conclusion was based on the work of an FAA Industry Training Standards(FITS) research team consisting of partners from industry, academia, and the federal government (FITS Program Plan, 2003). This group, after an extensive review of the literature and actual observation of current training practices, concluded that meaningful practice of real world situations expressed as scenario based training would improve the pilots ability to cope with ambiguous situations, make more informed and timely decisions, and ultimately improve safety.

\section{Statement of the problem}

The TAA is not inherently dangerous yet its advanced equipment, especially the addition of an extremely accurate moving map navigation capability, can lure pilots into increasingly complex situations. Traditional task and maneuver-based training may not prepare the pilot to understand or adapt to these new situations (Davisson, 2003). Additionally, the speed, comfort, and costs associated with this new generation of TAA's increase their usefulness as alternatives for commercially available air transportation without providing a comparable increase in the level of safety (Wright, 2002). Thus, this study focuses on training. If the aircraft has improved, and the mission is more complex, the remaining variable is the training and experience of the pilot.

\section{Scenario based training}

In order to understand the training option available in the broader aviation industry, the author visited the United States Air Force training facilities at Moody Air Force Base, Georgia and Columbus Air Force Base, Mississippi. Both of these facilities train pilots with relatively few flying hours, who are then qualified to fly modern glass cockpit very high performance jet aircraft. These pilots fly the aircraft in a variety of complex mission scenarios. In each case the Federal Aviation Administration endorses the quality of these graduates, while not regulating their specific training flow or training methods (CFR Part 61:73). Both locations employed various methods of mission oriented flight 
training which gave the student meaningful practice in real world situations.

A visit by the author to Northwest Airlines revealed similar training methods employed in the Line Oriented Flight Training (LOFT) portion of the Boeing 757 training curriculum. In this case, more traditional training methods were utilized up until the final lesson, which is conducted as a realistic flight scenario, and is used to measure the applicant's suitability to operate the aircraft with passengers on board (SFAR No: 58 to part 121). During each observation, the primary training in pilot judgment and decision-making occurred during realistic flight scenarios.

While scenario based training is not a new concept, its application to General Aviation on a larger scale represents a significant change. Traditionally, General Aviation has relied upon a combination of behavioral and cognitive learning strategies that place a premium on student knowledge acquisition and repetitive behavior. This approach is very useful when training a student to accomplish specific maneuvers or to learn specific tasks, or sequences of tasks. The FAA Aviation Instructor handbook, AC 60-14, which serves as the guide to General Aviation flight instructors, is deeply grounded in this behavioral and cognitive approach (1999).

However, the goal of the FITS research effort is to "enhance the General Aviation pilots' aeronautical decision making, risk management, and single pilot resource management skills" (FITS website). This involves the application of knowledge to a variety of ambiguous situations. Gagne, Briggs, and Wager theorize that this type of problem solving may be best taught by providing the student with a "larger and better organized knowledge base" (1992, pp. 72). This would seem to indicate that the greater the experience and knowledge about the system, the greater the probability of success in problem solving. However, Gagne expresses some doubt that these "executive or metacognition strategies" can be taught, instead, theorizing that learners develop them from a "variety of task oriented strategies" (1992, pp. 74-75).

Another opinion, and the one under consideration in this study is that a constructivist approach to learning may provide a better way to teach problem solving skills (Duffy and Jonassen, 1992). Constructivism revolves around the development of a mental model or schema constructed by exposure to a realistic and complex environment. The problem for pilots transitioning from older and simpler aircraft to the complexity of the TAA is the simultaneity of learning and un-learning that must go on to master the new skills required. The highly automated TAA cockpit changes almost every aspect of the pilot's relationship with the aircraft's controls and indicators. Thus, much of what was learned previous to exposure to the TAA is now of diminished value. At the same time the TAA requires new skills more closely associated with personal computers than with aircraft instrumentation. In fact, a relatively new term, "automation bias" is used to identify the "omission and commission errors resulting from the use of automated cues as a heuristic replacement for vigilant information seeking and processing" (Burdick et al., pp. 48-50). Thus, a pilot transitioning to a TAA is simultaneously forced to learn new information while constantly evaluating the accuracy and utility of previously known and accepted facts.

Malcolm Knowles, an acknowledged expert on adult education, speaks of this as he draws parallels between adult education theory and constructivism (1992). Constructivism appeals to the adult learner desire to control the learning process and evaluate it in light of previous experience (Knowles, 1992). In sum, constructivists and adult educators should agree that problem solving will be best learned in a realistic environment, based on authentic tasks, and grounded in experiential learning. In the end, the student will learn a "way" to think about a given set of circumstances, instead of simply "what" to think about a set of specific problems. Building on the observations from the military and air carrier operations, the research indicates that a constructivist approach to learning, when integrated with the more traditional behavioral and cognitive strategies may prove very effective in developing higher order judgment and decision making skills.

\section{Background}

The air carriers discovered that these higher order judgment and decision-making skills were best understood within the framework of a concept called Cockpit Resource Management (CRM). CRM is generally defined as the utilization of all potential resources that are available to the crew in making decisions (Weiner, 1993). In the commercial airline industry, these resources can include but are not limited to; pilots, flight attendants, dispatchers, mechanics, Air Traffic Control, and additional crewmembers. CRM emphasizes the ability to effectively communicate. How a person communicates, how information is exchanged, how one behaves, and how decisions are made, are all components of a CRM program. CRM, amongst other things, teaches pilots how to improve communication, prioritize tasks, delegate authority, and monitor automated equipment (Baron, 2003).

\section{Single Pilot Resource Management (SRM)}

Since the TAA is more similar in design and operation to 
air carrier aircraft than the traditional General Aviation aircraft, the FITS research team felt a version of CRM tailored to the unique requirements of the single pilot TAA was warranted. This construct is called Single Pilot Resource Management (SRM). SRM is defined as "The art and science of managing all the resources (both on-board the aircraft and from outside sources) available to a single pilot (prior and during flight) to ensure that the successful outcome of the flight is never in doubt" (Ayers, 2003). It is further subdivided into the distinct areas of task management, automation management, situational awareness, risk management, and controlled flight into terrain (CFIT) awareness as depicted in table 1.

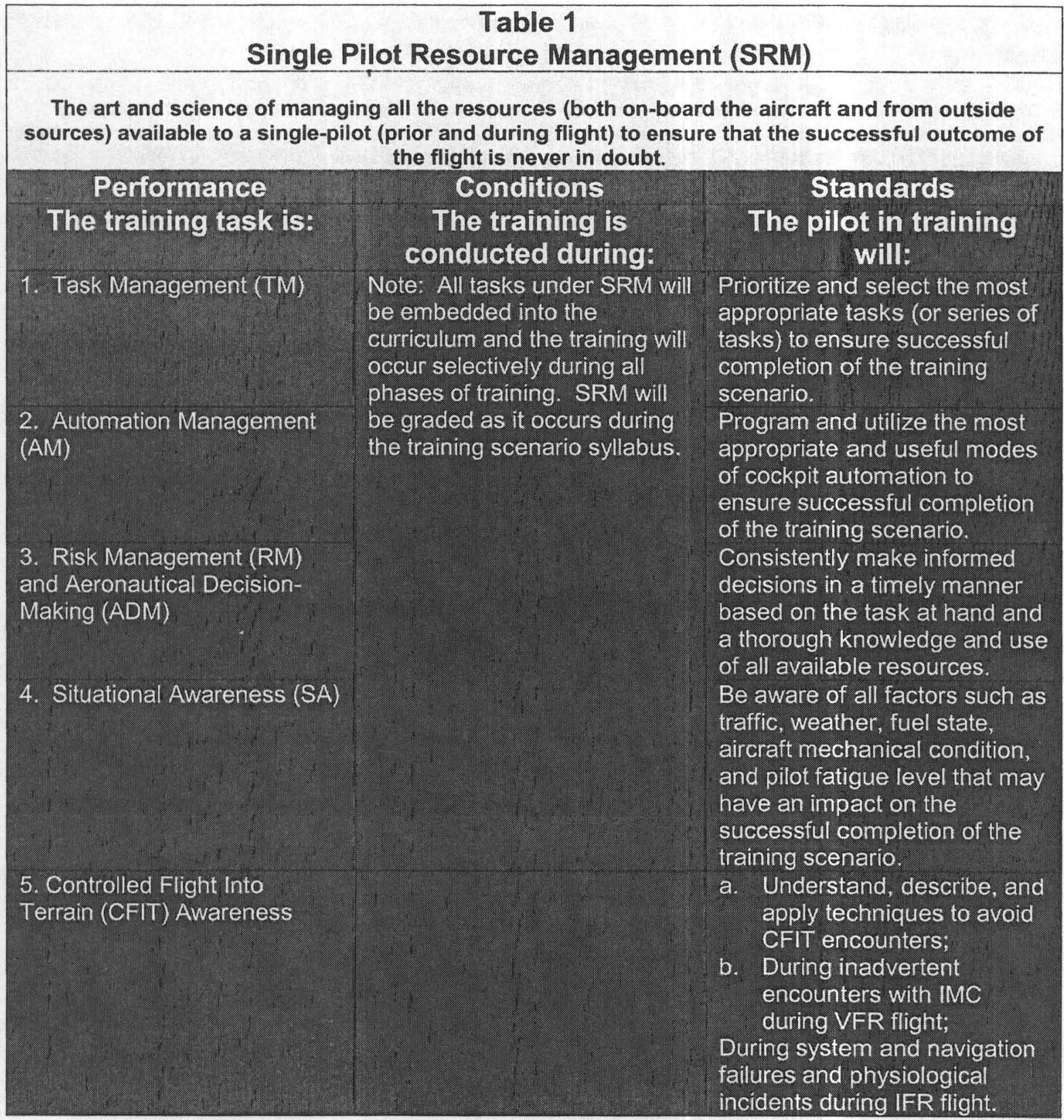

(FITS Piston Technically Advanced Aircraft Recurrent Training Syllabus, 2004) 
Taken as a whole, these concepts address the majority of the risk inherent in single pilot, single engine flight. Since these concepts are dependent on the existing flight situation, the choice of a scenario based learning approach seemed logical.

So logical that Mr. Robert Price, Director of Operations and Training for the Cirrus (the Cirrus was the first new technology aircraft to earn the title of TAA) Owners and Pilots Association (COPA) approached the author about developing a scenario based SRM seminar for the existing Cirrus Pilot Proficiency Program (CPPP). COPA agreed to allow the FITS research team to conduct some basic research on both SBT and SRM simultaneous to the training.

\section{METHOD}

The FITS team developed four distinct ground and flight scenarios that encompassed elements of all five SRM disciplines. Each scenario consisted of a pre-flight, pretakeoff, enroute, and arrival segment(s) that combined normal operations and procedures with abnormal and eventually emergency procedures. The scenarios were constructed using realistic situations that mirrored those routinely encountered by pilots of the Cirnus Aircraft. As the scenario unfolds, the participants were presented with inputs that either requires modification of the existing route and plan of action. While some inputs required little or no action, others required more immediate action. Each scenario required the pilot to change the flight plan and either divert or perform an emergency landing.

The seminars were designed for presentation by a knowledgeable facilitator, and were presented to groups of up to twenty participants. Each scenario consisted of a set of PowerPoint slides, supplemented by a script for the facilitator. Participants were provided with required flight planning documents during the presentations and were asked to respond as if they were in the actual aircraft. At each decision point, the facilitator presented the new information then asked for discussion from the group. The facilitator to increase the realism of the scenario added additional scripted, and occasionally improvised, inputs.

\section{Participants}

A total of 54 pilots participated in a total of four seminars conducted at two separate CPPP sessions, the first in St Augustine Florida, and the second conducted in Las Vegas Nevada. The largest seminar numbered 17 and the smallest 10 participants. Participants varied in age from 25 to 65 years of age and from 150-hour private pilots to several thousand-hour airline captains. In order for the scenario based, constructivist approach to be effective, several ground rules were agreed to beforehand. The facilitator acted as the moderator to ensure the scenario remained on track and the appropriate learning objectives were achieved. First, the participants agreed in advance that nothing said in the room would be associated with an individual participant after the seminar ended. This was done to ensure free and open communication. Second, the participants agreed that there would be no personal criticism of participant inputs. Rather, the merits of the opinions presented would be discussed. Since judgment and decision-making is based on the individual's perception of the situation, individual knowledge and experience, and tolerance for risk, all participants were allowed to manage their own risk factors and learn the lessons they deemed important. The facilitator refrained from enforcing his will on the class at any time. This approach seemed to be effective as each seminar started out a little tentatively, but by the time the first scenario was completed, the discussion and debate were often vigorous.

The seminars were divided into a morning and afternoon session, each lasting three hours. The seminars followed two days of intensive task-based flight training and fact-based ground training administered by the CPPP staff. At both locations the last scenario in the seminar was custom built to represent the typical CPPP participants most likely flight home that evening. In St. Augustine a flight to Washington, D.C. was the last scenario, and in Las Vegas a flight to Los Angeles concluded the day. Interestingly, the weather in the St. Augustine return scenario was almost identical to the weather forecast for the east coast that evening, causing several participants to decide to remain over night until the situation improved. Thus, the SRM seminars formed a sort of capstone to the CPPP program.

\section{Survey construction and administration}

Two separate survey instruments were used to evaluate the SRM seminars. The first instrument (appendix 1) was developed just prior to the St. Augustine seminar and was administered to 27 participants during two separate seminars. It is based on Kirkpatrick's four levels of training evaluation and attempts to obtain a snapshot of the participant's opinions on the enjoyment, understanding, and eventual employment of the subject presented (Hohne, 2000). Additionally, the survey asked participants to rate whom they learned the most from, the instructor, the group, or their own reflection on the material presented. Finally, each participant was asked to identify the best part of each seminar as well as the one item they would change if they could.

Based on the results of the first survey, the second survey 
instrument included similar questions, but posed several additional questions pertaining to the quality and realism inherent in the scenarios. The written portion of the survey changed as well, asking the participants to identify the three best parts of the seminar, and three areas for improvement.

. During each of the seminars, the facilitator (the author facilitated all four seminars) observed the level of participation, student interest in particular scenarios, and ease of preparation and delivery. These observations are included in the results. At the end of each scenario the participants were asked if they would be willing to participate in a longitudinal study of their' attitudes and performance. Every participant agreed to participate by leaving a name, phone number, or E-mail address.

\section{RESULTS}

The data shows that a clear majority of participants in both seminars found the training enjoyable, interesting and the subject matter useful. In the St. Augustine seminar, the three highest rated answers were: (1) "Do you understand the basic philosophy of SRM" (4.93/ 5.00); (2) " Did you feel the subject was worthy of discussion and enjoyable" (a tie at 4.89 /5.00; and (3) "Will you consider using SRM" (4.85/5.00).

At the Las Vegas seminar the three top answers were: (1) "is scenario discussion an effective teaching tool " (4.56/5.00); (2) "will you implement SRM into your flying habits" (4.48/5.00); and (3) a three way tie between "scenario realism", "the use of mental imagery to rehearse flight scenarios", and "the practice of SRM after the course"(4.41/5.00).

Several specific results stand out. A clear majority of participants in the Las Vegas seminar had experienced very little scenario-based training (this item was not measured at St Augustine) prior to attending the CPPP. This is significant since most participants had received significant amounts of aviation training. In St. Augustine, most felt they learned more from the group discussion than from their own reflection on the subject. This fact was born out by the author's personal observations of the lively and candid discussion that accompanied each seminar. In fact, on several occasions the discussion became spirited to the point of good-natured debate.

The greatest insights may be obtained by reading the written inputs of the participants. Over half of the participants wrote about the scenarios, enjoying them, wanting more of them, or wanting more realistic ones. In any case the majority of participants seemed to realize that they learned best during these opportunities to mentally rehearse and practice real life situations. Even the areas for improvement comments reflected the desire for fewer introductory events and more and better scenarios. Many wanted to see the scenarios taken to the next level through the use of desktop simulation. This combination of interest in the scenarios and an initial commitment to change seems to indicate the strength of the scenario based approach, as well as the content.

\section{DISCUSSION}

First, the participants and the course developers agree that realistic scenario development is both challenging and critical to the success of SBT. A comparison of the first and second seminar survey results appears to indicate significant progress was made in this area. Second, the facilitator needs to be comfortable guiding the discussion to a reasonable conclusion and tolerant of the different experience levels in the class. Several times, the class would diverge on a critical go-no-go decision based on their individual levels of experience and training. This actually turned out to be quite helpful. Those who had already decided to continue the flight were forced to consider the risks that others saw in that decision and those who chose to abort the flight saw how the more experienced pilots managed risk and made decisions, a positive result for both groups. Third, the more realistic the scenarios the better learning improves. The high point of the Las Vegas seminar (and of all the sessions) occurred as a loss of control scenario was presented to the Cirrus pilots at a low altitude (1500 feet). Spontaneously, Mr. Bob Price of COPA began to forcefully call out the descending altitudes to the class in real-time, forcing a decision to use the Cirrus Aircraft Parachute System (CAPS) (the CAPS system is a new safety innovation that allows the entire aircraft to descend to the ground under a parachute canopy). The group reaction to this life or death situation was at once visceral and chaotic. The realization that very little time would elapse between the onset of spatial disorientation and ground impact was a lesson that could only be experienced (even if only verbally simulated) safely in the scenario discussion. One participant wrote later that the experience was 'sobering."

\section{CONCLUSIONS AND RECOMMENDATIONS}

Scenario Based Training and Single Pilot Resource Management appear to be at least initially effective in helping pilots understand how to respond to abnormal and emergency situations. The combination of the behaviorist, cognitivist, and finally the constructivist approaches to training encompassed in the three day CPPP seminars seemed to compliment each other and produce pilots capable of knowing "how" to think as well as "what" to think. Possibly the strongest endorsement of this concept is 
the recent COPA decision to integrate the SRM scenarios as a permanent addition to the CPPP curriculum.

While the initial results appear promising, much work remains to be done. Additional research on the quality and quantity of scenario inputs will increase the effectiveness of SBT. A longitudinal study on the graduates of the CPPP seminars is underway and will be the subject of a follow-up paper. Finally, additional research to more fully develop the concept of SRM should provide better insights into why and how pilots can reduce risk and make more timely and informed decisions. $\rightarrow$

Francis H. (Frank) Ayers Jr. is the Principal Investigator for the FAA Industry Training Standards research program. He is the Chairman of the Flight Department and an Associate Professor of Aeronautical Science at Embry Riddle Aeronautical University in Daytona Beach, Florida. Professor Ayers holds the Airline Transport Pilot and Certified Flight Instructor certificates and has over 5,000 flight hours. He is currently pursuing a Doctorate in Education at NOVA Southeastern University. 


\section{REFERENCES}

Ayers, F., Robertson, C, \& Connolly, T. (2004, January 26), FITS Piston Technically Advanced Aircraft Recurrent Training Syllabus and Standards, Version 1.0, http://wwwl faa.gov/avr/afs/fits/,

Baron, R. (2003). CRM: From the instructor's viewpoint. Retrieved October 30, 2003 from http://www.airlinesafety.com

Burdick, M., Heers, S., Mosier, K. and Skitka, L. (1998) Automation bias: Decision making and performance in high tech cockpits. The International Journal of Aviation Psychology. 8.,1

Cirrus Owners and Pilots Association (COPA) Website, Retrieved May 9, 2004 from http://www.cirruspilots.org/public/cppp/syllabus.html

Davisson, Budd. (2003). Margin of Safety: Understanding the Risks of Marginal VFR. AOPA Flight Training, 15(3), 20-24.

Duffy, T. M., and Jonassen, D.H. (1992). Constructivism and the technology of instruction: a conversation. New jersey., Lawrence Ehrlbaum and Associates

FAA-Industry Training Standards (FITS) Program Plan. Retrieved May 9, 2004 from http://www.faa.gov/avr/afs/fits/program/program\%20plan.doc

Fiduccia, P., Wright, B., Ayers, F., Edberg, J., Foster, L., Henry, M., et al. (Aug 22, 2003). General Aviation Technically Advanced Aircraft FAA-Industry, Safety Study, Final Report. Retrieved 05/09/04 from http://www.faa.gov/avr/afs/fits/documents/TAA\%20Final\%20Report.pdf

Gagne, R.M., Briggs, L.J., and Wager, W. (1992). Principles of Instructional design. New York: Harcourt, brace, and Jovanovich.

Hohne, C. K., King, S. B., \& Rothwell, W.J (Eds.). (2000). Human Performance Improvement, Building Practitioner Competence. Houston, TX. Gulf Publishing

Knowles, M., Holton, E., \& Swanson, R. (1998). The adult learner: The definitive classic in adult education and human resource development. Wobern, MA, Butterworth-Heinemann

U.S. Department of Transportation. (1999). Aviation instructors handbook. Washington D.C.

U.S. Department of Transportation. (2004). Code of Federal Regulations, FAR Part 61:73. (2004). Military pilots or former military pilots: special rules. Washington D.C.

U.S. Department of Transportation. (2004). Code of Federal Regulations, SFAR No: 58 to part 121. (2004). Advanced qualification program.

Washington D.C.

Weiner, E. L., Kanki, B.G., \& Helmreich, R.L. (1993). Cockpit resource management. London. Academic Press.

Wright, R. A., (April 2002). Changes in general aviation flight operations and their impact on systems safety and flight training. An unpublished white paper prepared for the Federal Aviation Administration. Retrieved on May 9, 2004 at http://www.faa.gov/avr/afs/fits/program/whitepaper.doc 


\section{Appendix A \\ COPA CPPP Seminar, \\ St Augustine Florida, 25 January, 2004 \\ Yes Some Maybe Little No \\ $\begin{array}{lllll}5 & 4 & 3 & 2 & 1\end{array}$}

Average Score

1. Did you enjoy the presentation and discussion of SRM?

$\begin{array}{lllll}25 & 1 & 1 & 0 & 0\end{array}$

\section{$132 / 27=4.89$}

2. Did you feel the subject is worthy of discussion?

2610000

\section{$132 / 27=4.89$}

3. Do you feel you understand the basic philosophy of SRM?

\section{$133 / 27=4.83$}

25200000

4. Do you feel SRM might be of use in your daily flying?

$\begin{array}{lllll}24 & 2 & 1 & 0 & 0\end{array}$

\section{$130 / 27=4.81$}

5. Do you feel you were given practical ways to implement SRM?

$\begin{array}{lllll}18 & 8 & 1 & 0 & 0\end{array}$

\section{$124 / 27=4.59$}

6. Did you find the scenario(s) enjoyable?

\section{$124 / 26=4.77$}

21

4

1

10

7. Did you learn something useful during the scenario(s)?

23

3

1

00

\section{$130 / 27=4.81$}


Yes Some Maybe Little No

8. During the flight scenario(s) who did you learn the most useful information from:

The instructor

\section{$116 / 25=4.64$}

$\begin{array}{lllll}17 & 7 & 1 & 2 & 0\end{array}$

The entire discussion group:

\section{$104 / 25=4.16$}

$\begin{array}{lllll}10 & 11 & 3 & 1 & 2\end{array}$

Your own reflection on the material :

9

10

32

3

\section{$98 / 24=4.08$}

9. Based on this experience will you consider using SRM

\section{$131 / 27=4.85$}

10. Would you like to know more detailed information about SRM?

\section{$130 / 27=4.81$}

0 0 


\section{COPA CPPP Seminar, \\ St Augustine Florida, 25 January, 2004 \\ Participant Written Comments}

Question !: What is the best single part of the presentation?

1. No (right or wrong) answer -3 people

2. Scenarios -7 people

3. The scenarios and discussions -4 people

4. Addressing different personalities on decision making and flight.

5. Recognize your weaknesses and strengths.

6. Group involvement

7. Well prepared

8. Structure - the 5 P's

9. The stories and interactions

10. As the last presentation at CPPP it was very effective in placing the BIG picture into perspective.

11. The progression of the scenarios to worse and worse conditions.

12. Thought process/mental stimulation/hypothetical recreating to actual contemplation was very useful.

13. New approach to flight safety.

14. Offers a plan to analyze the issues.

15. Single pilot IFR would like help.

16. Nice

17. Slides

Question 2: If you could improve one thing about this presentation, what would it be?

1. No answer -8 people

2. Multiple risk assessment applications 5 P's/Paul/ Risk management numerical value/ discussions on personal minimums.

3. Why do pilots take a course like this (or a similar King Course) and listen, nod heads, and then think "it doesn't apply to me?"

4. Nothing

5. Faster pace on the initial slides/more time on sample scenarios

6. Less predictable scenarios -2 people

7. More detail of what each "P" in the 5 P's can cover

8. Less introduction (authors note, introduction was the only "lecture" portion)

9. More time -2 people

10. More scenarios -2 people

11. A more standardized way of implementing SRM of advice on developing SRM system for the pilot.

12. Add a pilot flying and a pilot not flying checklist

13. Provide handouts of all presented materials -2 people

14. Less interactive

15. Use desktop computers to increase the scenario realism 


\section{Single Pilot Resource Management Survey \\ COPA CPPP Seminar, 14 March, 2004 \\ Las Vegas, Nevada}

A Great Deal/A Lot /Some/A Little/ Not at all / Total Score

$\begin{array}{lllllll} & 5 & 4 & 3 & 2 & 1\end{array}$

Please circle your answer

1. Have you ever attended scenario based training presentations?

$$
\begin{array}{lllll}
1 & 2 & 7 & 7 & 10=58 / 27=2.15
\end{array}
$$

2. Prior to this seminar, did you know anything about SRM?

$$
\begin{array}{lllll}
0 & 1 & 9 & 10 & 7=58 / 27=2.15
\end{array}
$$

3. Do you feel you understand the basic principles of SRM?

$$
8 \quad 15 \quad 3 \quad 1 \quad 0=111 / 27=4.11
$$

4. Do you think you will implement SRM into your flying habits?
13
140
$\mathbf{0}$
$0=121 / 27=4.48$

5. Did you think the scenarios were realistic?
12
141
$\mathbf{0}$
$0=119 / 27=4.41$

6. Did you learn anything useful from the scenarios?
12
114
0
$0=116 / 27=4.30$

7. Do you think scenario discussion is an effective teaching tool?
15
12
$\mathbf{0}$
0
$0=123 / 27=4.56$

8. Could you mentally visualize yourself acting out the scenarios?
11
13
2
o
$0=113 / 27=4.19$

9. Will you continue to use mental imagery to rehearse flight scenarios?
11
16
$\mathbf{0}$
o
$0=119 / 27=4.41$

10. Will you practice SRM after this course?

1312

$0 \quad 0=119 / 27=4.41$ 
COPA CPPP Seminar, 14 March, 2004

Las Vegas, Nevada, Participant Written Responses

Question 1: What are the top three best parts of the scenario presentations?

1. The idea of continuous re-evaluation of the flight in progress

2. Bringing passengers into the equation

3. The concept, that decisions may change based on equipment

4. New concept of 5 P's - 2

5. Think about actual scenarios

6. Think about slowly increasing level of risk

7. Quality instructors who have excellent presentation skills and are experienced in general aviation

8. Great delivery by Frank - 4

9. Realistic scenarios - 9

10. Good participation/discussion by group -10

11. The card reminder

12. The visual presentations

13. Multiple decisions - 2

14. What if's - 2

15. Preparing for emergencies

16. Organization

17. Looking at actual flight plans, charts, etc, and consider what I would do

18. Knowledge and style of presenter -3

19. Emphasis on process

20. Mostly practical situations

21. 1500 feet spatial disorientation on final scenario prompts rehearsing use of CAPS when focused on flying/recovering the airplane

22. The power point presentation

23. Focus on avionics used as an option

24. Decisions surrounding flying

25. All good!!!

26. Concept

27. Avionics aids

28. Discipline to do a thoughtful plan

29. No wrong answers

Question 2: If you could improve three things about this seminar, what would it be?

1. Incorporate movies of what the primrose path looks like

2. Offer it independently or CPPP

3. Audio/visual

4. Simulator training

5. Nothing -17

6. Continue development of the program to add a second phase 
7. Hard to imagine

8. The portion in which the instructor ticked off altitude and airspeed was effective in showing the time frames involved in emergencies. This kind of tactic should be amplified.

9. More of the plane's resources worked into the scenarios along with actual glitches that have occurred

10. More realistic scenarios like the last one - radio failure

11. More - longer

12. Profile views of terrain in presentation scenarios

13. I was not familiar with airports or routes, so instead of abbreviations, use airport names.

14. For route changes, color them in on slides so we know/see where we're going 
Journal of Aviation/Aerospace Education \& Research, Vol. 15, No. 2 [2006], Art. 8

, 